Jurnal Informatika dan Rekayasa Perangkat Lunak (JATIKA)
Vol. 2, No.3, September 2021, page-page. 353 360
ISSN 2723-3367
E-ISSN 2797-3492
available online at:http://jim.teknokrat.ac.id/index.php/informatika

\title{
ANALISIS DAN PERANCANGAN APLIKASI PEMESANAN TIKET BUS BERBASIS ANDROID
}

\author{
Alwi Marta Suzana \\ Universitas Teknokrat Indonesia \\ alwi_martasuzana@teknokrat.ac.id
}

Published: 30 September 2021

\begin{abstract}
PO Puspa Jaya is a company that is growing rapidly and is a company that is taken into account in land transportation services in Lampung. but in its service puspa jaya still perform manually, such as ticket booking, departure schedule information, and payment transactions carried out at pull puspa jaya. For that, there is a need for supporting facilities to book tickets at pull puspa jaya. From this problem came the idea to create an android-based application, which can make bus ticket reservations in po puspa jaya. The method used in the creation of applications is the Waterfall method. Programming language used by Android studio. With a MYSQL support database. The testing method used is ISO 9126 (Usability, Fungtionality, Portability, Efficiency). Supported by the internet connection in the agency. This application will later be used as a medium of ticket booking and passenger data control. This application is for several features, namely determining the time and destination of departure, choosing the desired seat, tray information, contact information and information about. The ticket booking application in po puspa jaya has been tested using ISO 9126 which consists of four aspects of testing namely Usability, Fungtionality, Portability, Efficiency. The Usability aspect obtained an $80.50 \%$ result with a decent record. Fungtionality gets $100 \%$ results.
\end{abstract}

Keywords: Android, Apps, Bookings, Tickets.

\begin{abstract}
Abstrak
PO Puspa Jaya merupakan sebuah prusahaan yang sedang berkembang pesat dan merupakan prusahaan yang diperhitungkan dalam jasa angkutan darat di Lampung. namun dalam pelayanannya puspa jaya masih melakukan secara manual, seperti pemesanan tiket, informasi jadwal keberangkatan, dan transaksi pembayaran yang dilakuan di pull puspa jaya. Untuk itu diperlukan adanya sarana penunjang untuk memesan tiket di pull puspa jaya. Dari masalah tersebut muncul gagasan untuk membuat suatu aplikasi berbasis android, yang didalamnya dapat melakukan pemesanan tiket bus di po puspa jaya. Metodelogi yang digunakan dalam pembuatan aplikasi adalah metode Waterfall. Bahasa pemograman yang digunakan Android studio. Dengan database pendukung MySQL. Metode pengujian yang digunakan adalah ISO 9126 (Usability, Fungtionality, Portability, Efficiency). Didukung dengan adanya koneksi internet pada instansi. Aplikasi ini nanti nya akan di gunakan sebagai media pemesanan tiket dan pengontrolan data penumpang. Aplikasi ini di bagi beberapa fitur yakni penentuan waktu dan tujuan keberangkatan, memilih tempat duduk yang diinginkan, informasi trayek, informasi kontak dan informasi tentang. Aplikasi pemesanan tiket di po puspa jaya telah diuji menggunakan ISO 9126 yang terdiri dari empat aspek pengujian yaitu Usability, Fungtionality, Portability, Efficiency. Aspek Usability mendaptkan hasil 80,50\% dengan catatan layak. aspek Fungtionality mendapat hasil 100\%.
\end{abstract}

Kata Kunci: Android, Aplikasi, Pemesanan, Tiket.

To cite this article:

Alwi Marta Suzana. (2021). ANALISIS DAN PERANCANGAN APLIKASI PEMESANAN TIKET BUS BERBASIS ANDROID. Jurnal Informatika dan Rekayasa Perangkat Lunak, Vol(2) No(3), 353-360. 


\section{PENDAHULUAN}

Perangkat lunak (software) adalah program komputer yang terasosiasi dengan dokumentasi perangkat lunak seperti dokumentasi kebutuhan, model desain dan cara penggunaan /user manual (Ahdan et al., 2020; Dwijaya, 2020). Sebuah program komputer tanpa terasosiasi dengan dokumentasinya maka belum dapat disebut perangkat lunak (software) (Damayanti \& Sulistiani, 2017; Nugroho et al., 2021; Setiawansyah et al., 2021). Sebuah perangkat lunak juga sering disebut dengan sistem perangkat lunak. Sistem berarti kumpulan komponen yang saling terkait dan mempunyai satu tujuan yang ingin dicapai. Hal yang biasanya dilakukan secara manual, dengan adanya perangkat lunak bisa mengubahnya menjadi sebuah proses yang bisa dikerjakan dengan cepat, mudah dan efektif (Darwis et al., 2019; Purnama et al., 2018; Septilia et al., 2020).

PO Puspa Jaya merupakan sebuah perusahaan yang sedang berkembang pesat dan merupakan prusahaan yang diperhitungkan dalam jasa angkutan darat di Lampung. namun dalam pelay anannya puspa jaya masih melakukan secara manual, seperti pemesanan tiket, informasi jadwal keberangkatan, dan transaksi pembayaran yang dilakuan di pull puspa jaya dan sering juga terjadi penumpukan penumpang pada saat hari libur nasional atau hari libur keagamaan, yang mengakibatkan penumpang berdesak desakan untuk memesan tiket, yang disebabkan kuran nya jumlah unit bus yang beroperasi. Mengikuti perkembangan teknologi dibidang mobile device yang diterapkan pada sarana transportasi sangat jarang ditemukan pada transportasi bus yang melalui perangkat mobile, dimana perangkat mobile sudah didukung fitur internet (Muhaqiqin \& Rikendry, 2021). Hal ini dapat dimanfaatkan oleh perusahaan jasa transportasi darat untuk mengatasi permasalahan penyajian informasi khususnya dalam ketersedian tiket dan proses pemesan yang masih bersifat manual (Riskiono \& Reginal, 2018).

Identifikasi masalah yang akan di kembangkan berdasarkan latar belakang masalah diatas, maka solusi yang diusulkan dalam mengatasi masalah-masalah yang berkaitan dengan pemesaan tiket Bus di PO Puspa Jaya Bandar Lampung., Aplikasi berbasis Android yang dapat membantu memudahkan dalam proses pemesanan tiket (Nurmanto \& Gunawan, 2020; Puspaningrum et al., 2020). Perancangan pemodelan menggunakan pemodelan beriontasi pada Objek. Sehingga dibutuhkan sistem yang dapat membantu memudahkan dalam proses pemesanan tiket Kelebihan dari aplikasi pemesanan tiket yang akan dikembangkan yaitu dapat memilih tempat duduk yang diinginkan, dapat melihat waktu keberangkatan dan info tujuan keberangkatan.

\section{TELAAH PUSTAKA}

\section{Aplikasi}

Menurut (Roger S. Pressman, 2012) Perangkat lunak aplikasi adalah suatu sub kelas perangkat lunak komputer yang memanfaatkan kemampuan komputer langsung untuk melakukan suatu tugas yang diinginkan pengguna. Biasanya dibandingkan dengan perangkat lunak sistem yang mengintegrasikan berbagai kemampuan komputer, tapi tidak secara langsung menerapkan kemampuan tersebut untuk mengerjakan suatu tugas yang menguntungkan pengguna. Contoh utama perangkat lunak aplikasi adalah pengolah kata, lembar kerja, dan pemutar media. Beberapa aplikasi yang digabung bersama menjadi suatu paket kadang disebut sebagai suatu paket atau suite aplikasi (application suite). Contohnya adalah Microsoft Office dan Open Office.org, yang menggabungkan suatu aplikasi pengolah kata, lembar kerja, serta beberapa aplikasi lainnya. Aplikasi-aplikasi dalam suatu paket biasanya memiliki antarmuka pengguna yang memiliki kesamaan sehingga memudahkan pengguna untuk mempelajari dan menggunakan setiap aplikasi. Sering kali, aplikasi ini memiliki kemampuan untuk saling berinteraksi satu sama lain sehingga menguntungkan pengguna. Contohnya, suatu lembar kerja dapat dibenamkan dalam suatu dokumen pengolah kata walaupun dibuat pada aplikasi lembar kerja yang terpisah.

\section{Android}

Menurut (Lauren et al., 2013) Android adalah sebuah sistem operasi untuk perangkat mobile berbasis linux yang mencangkup sistem operasi, middleware dan aplikasi. Android menyediakan platform terbuka bagi para pengembang untuk menciptakan aplikasi mereka . Arsitektur android terdiri dari bagian-bagian seperti berikut :

a. Application dan Widgets : lapisan dimana para pengguna hanya berhubungan dengan aplikasi saja.

b. Aplication Framwork : lapisan dimana para pengembang melakukan pembuatan aplikasi yang akan dijalankan di sistem operasi android dengan komponen-komponennya meliputi views, contents provider, resource manager, notification manager, activity manager. 
c. Libraries : lapisan dimana fitur-fitur android berada diatas kernel meliputi library $\mathrm{C} / \mathrm{C}++$ inti seperti Libe dan SSL.

d. Android Run Time : lapisan yang membuat aplikasi android dapat dijalankan dimana dalam prosesnya menggunakan implementasi Linux yang terbagi menjadi dua bagian yaitu Core Libraries dan Dalvik virtual Machine.

e. Linux Kernel : Layer yang berisi file-file system untuk mengatur processing, memory, resource, driver, dan sistem operasi android lainnya.

Sistem operasi yang mendasi android dilesensikan dibawah GNU, GPlv2 (General Public License verse 2) yang sering dkenal dengan copyleft. PendistriBusian android dibawah lisensi dari Apache Software yang memungkinkan untuk distriBusi kedua dan seterusnya.

\section{METODE PENELITIAN}

\section{Teknik Pengumpulan Data}

Adapun metode pengumpulan data yang dilakukan penulis dalam penelitian ini adalah sebagai berikut:

\section{Wawancara (Interview)}

Pengumpulan data dengan metode interview yaitu metode pengumpulan data dengan cara tanya jawab secara langsung dengan pihak bagian oprasional khususnya dengan melakukan pertanyaan seputar sistem yang berjalan mengenai proses pemesanan tiket Bus.

\section{Pengamatan (Observation)}

Pengumpulan data dengan mengamatai atau observation yaitu metode pengumpulan data dengan cara pengamatan dan pencatatan secara langsung (Prayoga et al., 2020). Mempelajari segala sesuatu yang berhubungan dengan sistem dan mengamati secara langsung seputar sistem yang berjalan (Muhaqiqin \& Rikendry, 2021).

3. Studi Pustaka (Library Research)

Metode ini dilakukan dengan cara pengumpulan data melalui sumber-sumber bacaan yang berhubungan dengan data yang dibutuhkan, sehingga dapat menganalisa data yang akan disusun dalam menunjang penelitian (Styawati et al., 2020; Styawati \& Ariany, 2021).

\section{Dokumentasi (Documment)}

Merupakan metode pengumpulan data dengan cara membaca, mencatat, mengutip, dan mengumpulkan datadata secara teoritis dari buku-buku dan Internet sebagai landasan penyusunan penelitian (Ahdan \& Setiawansyah, 2021; Sulistiani et al., 2021). Meminjam buku di perpustakaan, mencari data dari internet juga dilakukan untuk referensi laporan ini, dimana teori tersebut diletakkan pada landasan teori (Juliyanto \& Parjito, 2021; Setiawan et al., 2021).

\section{Usecase Diagram}

Menggambarkan interaksi antara actor-actor dengan system yang dibangun, serta menggambarkan fungsionalitas yang dapat diberikan system kepada user. Dari dalam system yang akan dibangun terdapat dua actor yang masing-masing memiliki hak akses yang berbeda-beda yaitu user dan admin. User adalah masyarakat umum yang bias mengakses system informasi dan memesan tiket bus di PO. Puspa Jaya. Admin adalah pegawai di PO. Puspa Jaya yang khusus menangani tiketting. Proses usecase Diagram dapat di lihat pada gambar 3.2 sebagai berikut 


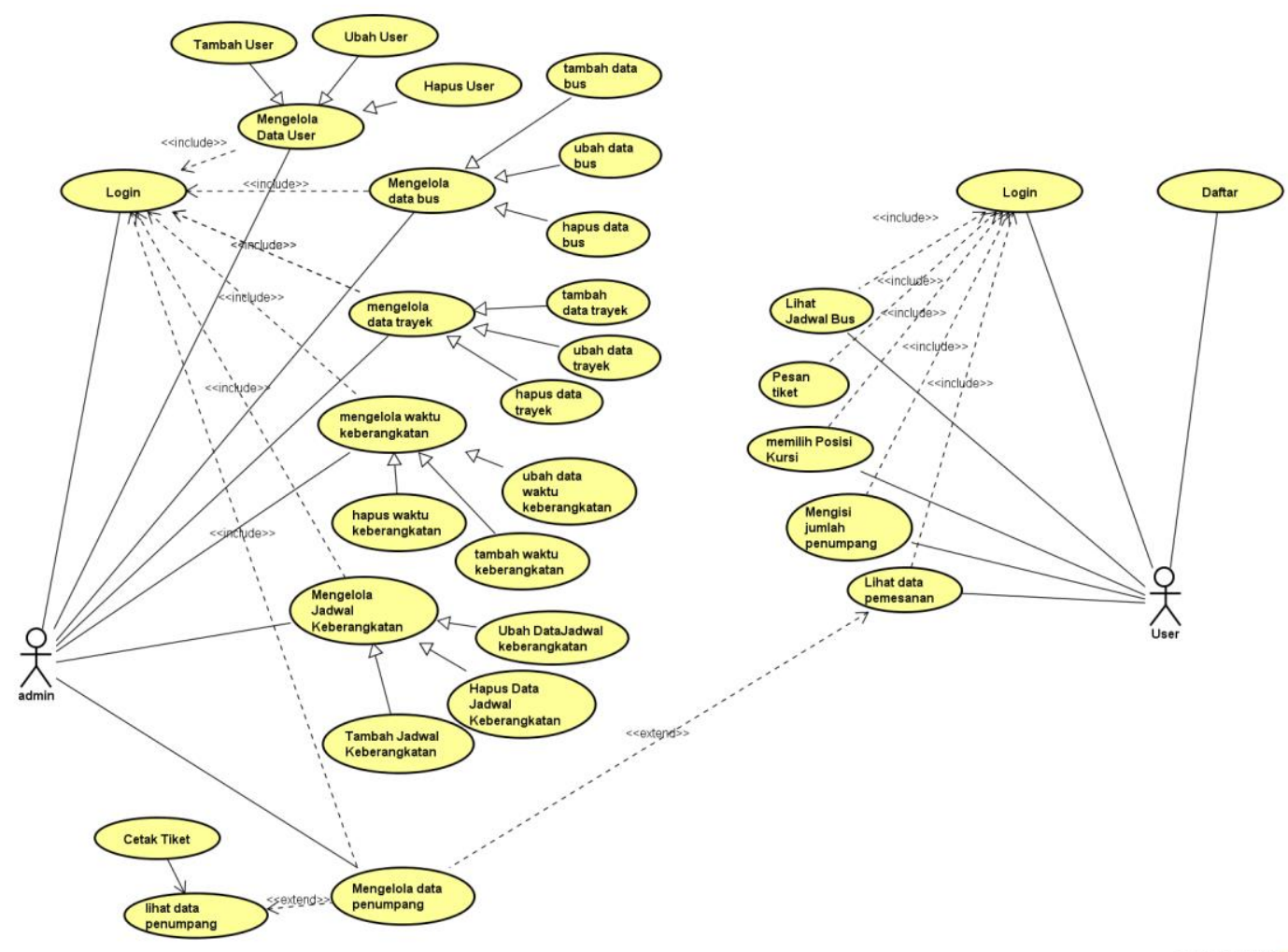

Gambar 1. Use case Diagram

\section{HASIL DAN PEMBAHASAN}

\section{Form Login Web}

Form login adalah tampilan awal ketika membuka web, dimana pengguna harus mengisi username dan password sesuai bagian masing-masing yang telah tersimpan di dalam sistem. Form login dapat di lihat pada gambar dibawah ini.

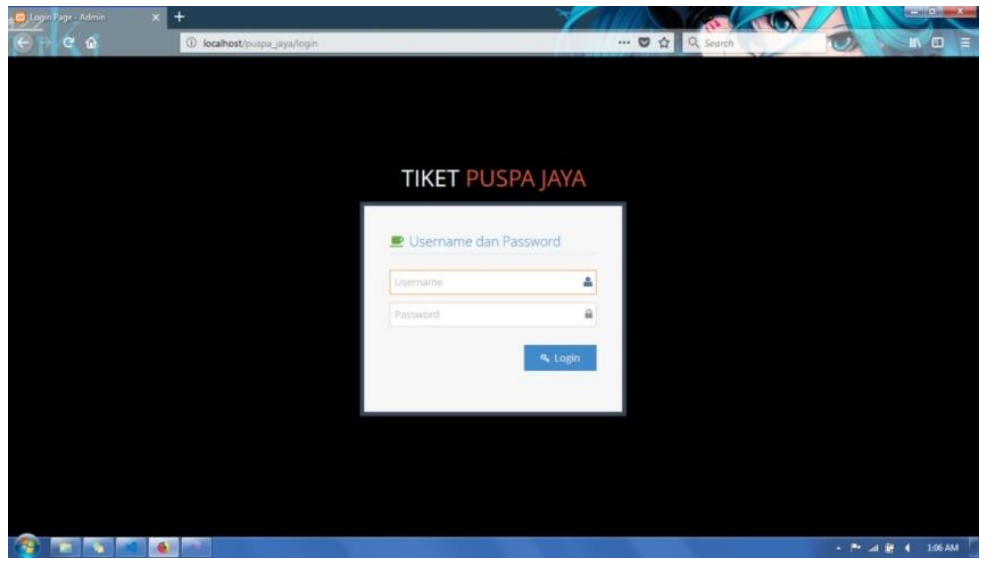

Gambar 2. form login

\section{Form Konfirmasi Tiket}

Form konfirmasi tiket berfungsi untuk mengecek penumpang yang sudah memesan tiket. Tampilan konfirmasi tiket dapat dilihat pada gambar dibawah ini 

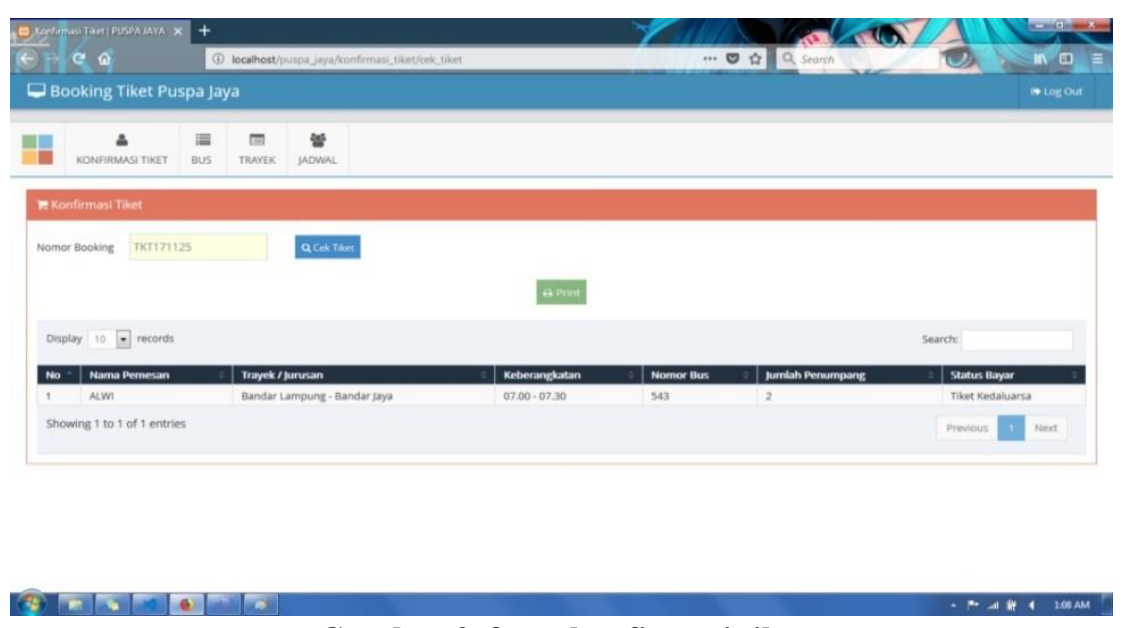

Gambar 3. form konfirmasi tiket

\section{Form Bus}

Form bus berfungsi untuk menambahkan data bus yang akan beroprasi seperti nomor bus, nomor polisi dan kapasitas bus.Tampilan form bus dapat dilihat pada gambar dibawah ini.

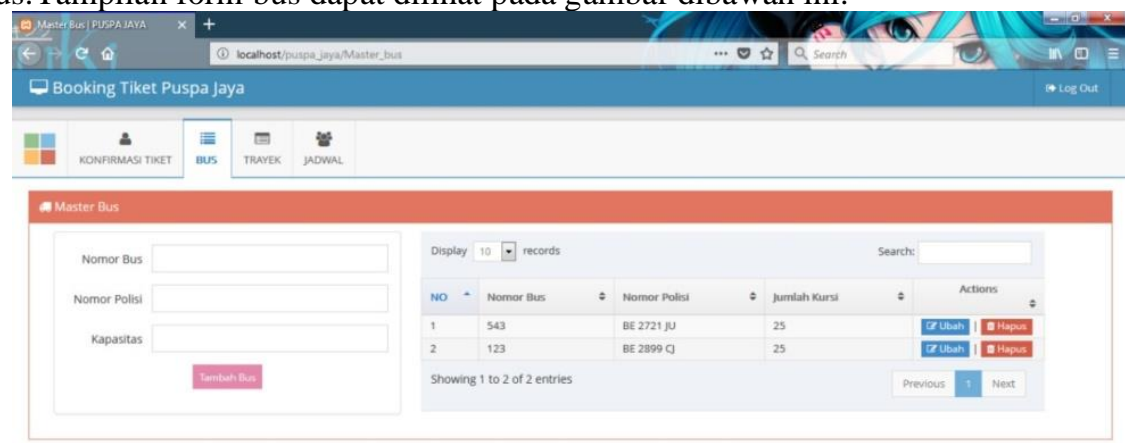

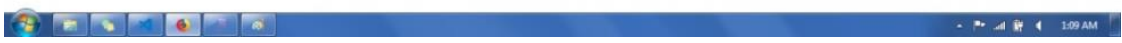

Gambar 4. form Bus

\section{Form Trayek}

Form trayek berfungsi untuk admin menginputkan tujuan keberangkatan bus serta harga tiker masing masing trayek. Tampilan konfirmasi trayek dapat dilihat pada gambar dibawah ini.

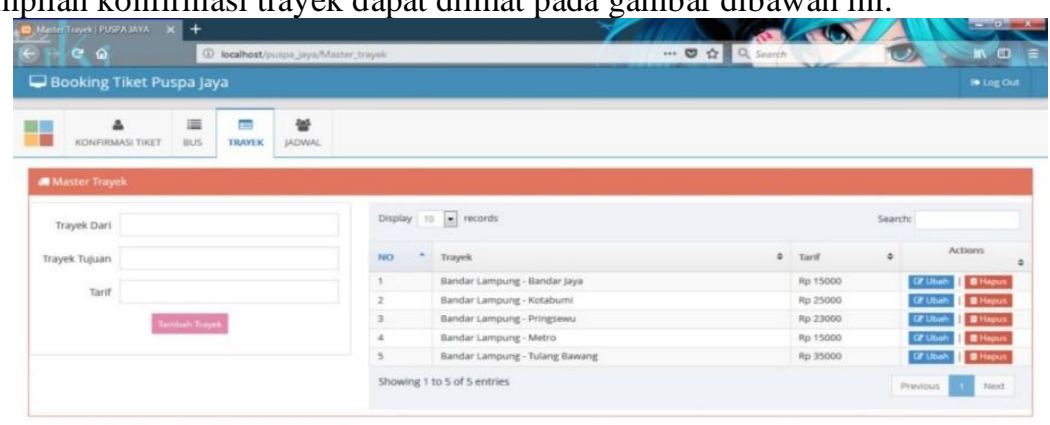

\section{Gambar 4. form trayek}




\section{Form Jadwal}

Form jadwal berfungsi untuk admin menginputkan jadwal keberangkatan terdiri dari armada bus, tanggal oprasional, jam keberangkatan dan trayek. Tampilan form jadwal dapat dilihat pada gambar dibawah ini

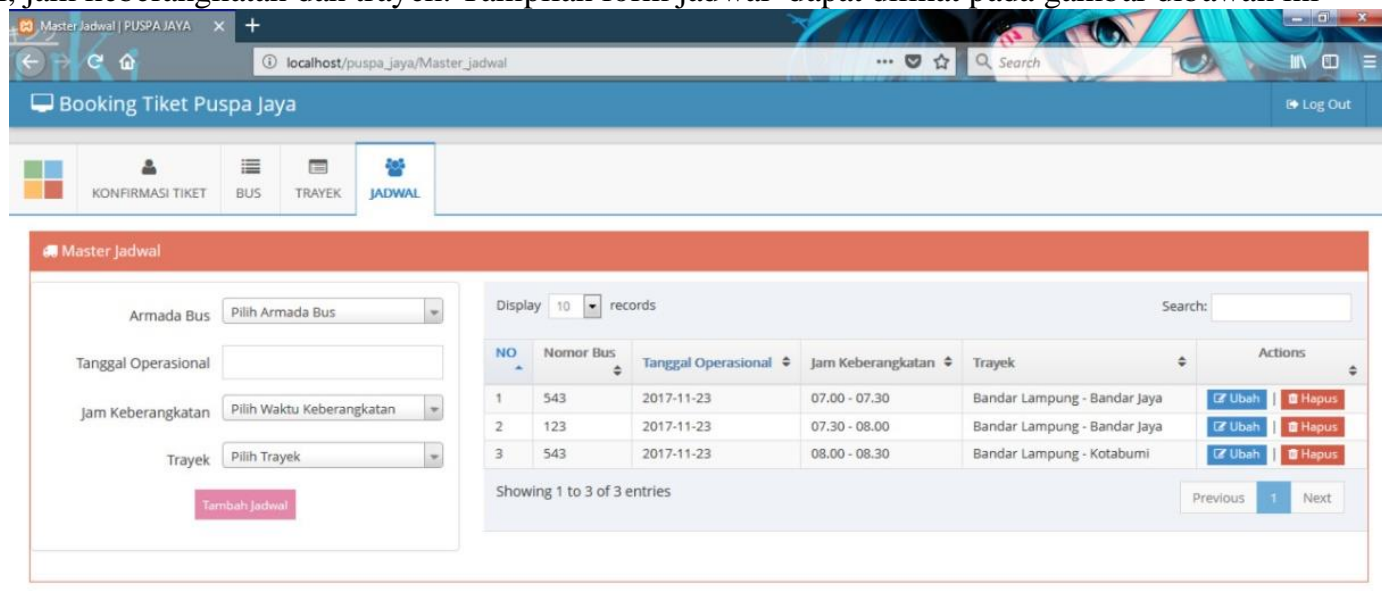

\section{Gambar 5. form jadwal}

\section{Form keberangkatan}

Form keberangkatan berfungsi untuk Admin mengatur waktu keberangkatan bus di setiap trayak jalan. Tampilan form keberangkatan dapat dilihat pada gambar dibawah ini.

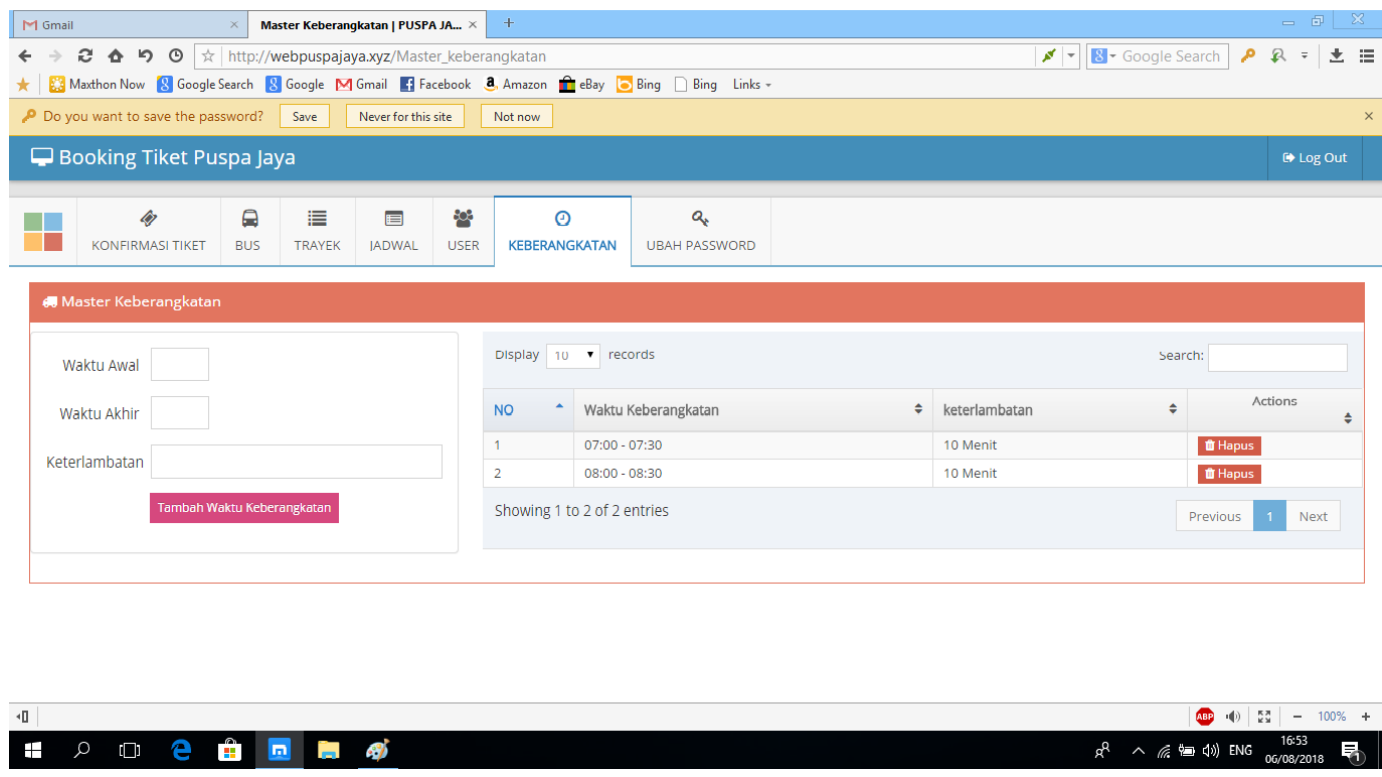

\section{Gambar 6. Form keberangkatan}

\section{Analisis Hasil Pengujian}

Aplikasi pemesanan tiket bus pada po puspa jaya diuji dalam tahap uji kualitas software berdasarkan ISO 9126 (functionality, usability, portability dan Efficiency). Hasil dari pengujian aplikasi media pembelajaran bahasa Lampung dapat dilihat pada Tabel 
Tabel 1. Hasil pengujian Aplikasi

\begin{tabular}{|l|l|}
\hline \multicolumn{1}{|c|}{ Aspek } & \multicolumn{1}{c|}{ Hasil } \\
\hline Functionality & Aplikasi dapat melakukan 100\% fungsinya dengan benar \\
\hline Usability & Pengujian aspek usability diperoleh nilai persentase sebesar 80,50\% \\
\hline Portability & $\begin{array}{l}\text { Aplikasi dapat di-install dan dijalankan pada device (smartphone) dengan sistem } \\
\text { operasi Android versi jelly Bean, Lolipop, Marshmellow dan Nougat dan diperoleh } \\
\text { persentase 100\% }\end{array}$ \\
\hline Efficiency & $\begin{array}{l}\text { Tidak mengalami kekurangan memory yang menyebabkan terjadinya memory leak } \\
\text { dan mengakibatkan aplikasi berhenti, penggunaan CPU maksimum oleh aplikasi } \\
\text { kurang dari } 60 \%\end{array}$ \\
\hline
\end{tabular}

\section{SIMPULAN}

Sistem pemesanan tiket berbasis Android dirancang untuk mempermudah penumpang (masyarakat) dalam memesan tiket, mengetahuai jadwal keberangkatan, trayek, dan juga dapat menetukan tempat duduk. Sistem ini terdiri dari beberapa fitur yaitu menu pesan tiket, menu konfirmasi, menu kontak, menu trayek dan menu tentang. Fitur fitur tersebut telah diuji menggunakan ISO 9126 yang terdiri dari empat aspek pengujian yaitu Usability, Fungtionality, Portability, Efficiency. Aspek Usability mendaptkan hasil 80,50\% dengan catatan layak. aspek Fungtionality mendapat hasil 100\%. dari keempat aspek yang sudah diuji, menunjukan aplikasi pemesanan tiket bus pada PO Puspa jaya berjalan dengan baik.

\section{REFERENSI/DAFTAR PUSTAKA}

Ahdan, S., Putri, A. R., \& Sucipto, A. (2020). Aplikasi M-Learning sebagai Media Pembelajaran Conversation pada Homey English. SISTEMASI: Jurnal Sistem Informasi, 9(3), 493-509.

Ahdan, S., \& Setiawansyah, S. (2021). Android-Based Geolocation Technology on a Blood Donation System (BDS) Using the Dijkstra Algorithm. IJAIT (International Journal of Applied Information Technology), 1-15.

Damayanti, D., \& Sulistiani, H. (2017). Sistem Informasi Pembayaran Biaya Sekolah Pada SD Ar-Raudah Bandar Lampung. Jurnal Teknoinfo, 11(2), 25-29.

Darwis, D., Pasaribu, A. F., \& Surahman, A. (2019). Sistem Pencarian Lokasi Bengkel Mobil Resmi Menggunakan Teknik Pengolahan Suara dan Pemrosesan Bahasa Alami. Jurnal Teknoinfo, 13(2), 71-77.

Dwijaya, D. A. (2020). PERANCANGAN APLIKASI UNTUK PELANGGARAN DAN PRESTASI SISWA PADA SMP KARTIKA II-2 BANDAR LAMPUNG. Jurnal Informatika Dan Rekayasa Perangkat Lunak, 1(2), 127-136.

Juliyanto, F., \& Parjito, P. (2021). REKAYASA APLIKASI MANAJEMEN E-FILLING DOKUMEN SURAT PADA PT ALP (ATOSIM LAMPUNG PELAYARAN). Jurnal Teknologi Dan Sistem Informasi, 2(1), 43-49.

Lauren, G., Kasus, S., Dreamweaver, M. M., Mysql, P. H. P., Mariana, N., Kardian, R., \& Lauren, G. (2013). KOMPUTASI. 12 .

Muhaqiqin, M., \& Rikendry, R. (2021). ALT+ F: APLIKASI PENCARIAN LAWAN TANDING FUTSAL BERBASIS MOBILE ANDROID. J-Icon: Jurnal Komputer Dan Informatika, 9(1), 81-87.

Nugroho, N., Rahmanto, Y., Rusliyawati, R., Alita, D., \& Handika, H. (2021). Software Development Sistem Informasi Kursus Mengemudi (Kasus: Kursus Mengemudi Widi Mandiri). J-SAKTI (Jurnal Sains Komputer Dan Informatika), 5(1), 328-336.

Nurmanto, D., \& Gunawan, R. D. (2020). PEMANFAATAN AUGMENTED REALITY DALAM APLIKASI MAGIC BOOK PENGENALAN PROFESI UNTUK PENDIDIKAN ANAK USIA DINI. 1(1), 36-42.

Prayoga, W. D., Bakri, M., \& Rahmanto, Y. (2020). Aplikasi Perpustakaan Berbasis Opac (Online Public Access Catalog) Di Smk N 1 Talangpadang. Jurnal Informatika Dan Rekayasa Perangkat Lunak, 1(2), 183-191.

Purnama, S., Megawaty, D. A., \& Fernando, Y. (2018). Penerapan Algoritma A Star Untuk Penentuan Jarak Terdekat Wisata Kuliner di Kota Bandarlampung. Jurnal Teknoinfo, 12(1), 28-32.

Puspaningrum, A. S., Suaidah, S., \& Laudhana, A. C. (2020). MEDIA PEMBELAJARAN TENSES UNTUK ANAK SEKOLAH MENENGAH PERTAMA BERBASIS ANDROID MENGGUNAKAN CONSTRUCT 2. Jurnal Informatika Dan Rekayasa Perangkat Lunak, 1(1), 25-35.

Riskiono, S. D., \& Reginal, U. (2018). Sistem Informasi Pelayanan Jasa Tour Dan Travel Berbasis Web (Studi Kasus Smart Tour). Informasi Dan Komputer, 06(02), 51-62.

Roger S. Pressman, P. D. (2012). Rekayasa Perangkat Lunak - Buku Satu, Pendekatan Praktisi. In Software Engineering : A Practitioner's Approach, Seventh Edition. https://doi.org/10.1098/rspb.2012.1110

Septilia, H. A., Parjito, P., \& Styawati, S. (2020). SISTEM PENDUKUNG KEPUTUSAN PEMBERIAN DANA BANTUAN MENGGUNAKAN METODE AHP. Jurnal Teknologi Dan Sistem Informasi, 1(2), 34-41.

Setiawan, M. B., Susanto, T., \& Jayadi, A. (2021). PENERAPAN SISTEM KENDALI PID PESAWAT TERBANG TANPA 
AWAK UNTUK KESETABILAN ROLL, PITCH DAN YAW PADA FIXED WINGS. The 1st International Conference on Advanced Information Technology and Communication (IC-AITC).

Setiawansyah, S., Adrian, Q. J., \& Devija, R. N. (2021). Penerapan Sistem Informasi Administrasi Perpustakaan Menggunakan Model Desain User Experience. Jurnal Manajemen Informatika (JAMIKA), 11(1), 24-36.

Styawati, S., \& Ariany, F. (2021). Sistem Monitoring Tumbuh Kembang Balita/Batita di Tengah Covid-19 Berbasis Mobile. J. Inform. Univ. Pamulang, 5(4), 490.

Styawati, S., Ariany, F., Alita, D., \& Susanto, E. R. (2020). PEMBELAJARAN TRADISIONAL MENUJU MILENIAL: PENGEMB ANGAN APLIKASI BERBASIS WEB SEB AGAI PENUNJANG PEMBELAJARAN E-LEARNING PADA MAN 1 PESAWARAN. Journal of Social Sciences and Technology for Community Service (JSSTCS), 1(2). Sulistiani, H., Sulistiyawati, A., \& Hajizah, A. (2021). Perancangan Sistem Pengelolaan Keuangan Komite Menggunakan Web Engineering (Studi Kasus: SMK Negeri 1 Gedong Tataan). Komputika: Jurnal Sistem Komputer, 10(2), $163-171$. 